\title{
KONSEP WAHYU MENURUT AL-QUR'AN
}

\author{
Herni Indriani \\ Jurusan Ilmu Hadis Fakultas Ushuluddin dan Adab Universitas Islam Negeri Sultan Maulana \\ Hasanuddin Banten \\ Herniindriani05@gmail.com
}

\begin{abstract}
Before the revelation of the Al-Qur'an was revealed to the Prophet Muhammad, the concept of revelation had existed in the Arab culture at that time. The concept at that time was related to poetry and prophecy which was thought to have come from the world of the jinn which was conveyed to poets and fortune tellers through a process of revelation. Revelation was a tremendous miracle sent down to prophets and messengers. This revelation was sent in accordance with something that will happen in this era, the revelation was sent through the angel Jibril, then the angel Jibril delivered it to the prophets and apostles who were willed by Allah. Revelation does not only come down to the Prophet Muhammad, but also to the prophets before the Prophet Muhammad. Besides that, in the context, the revelations that were sent to the Prophet Muhammad were not only al-quran, but also in the form of hadiths, both in the form of qudsi hadiths and hadiths of the Prophet. Among the mercy of Allah SWT towards humans that he not only gave them a clean nature that could guide and guide them towards goodness, but also from time to time he sent an apostle to mankind.
\end{abstract}

Keywords: concept, revelation, al-quran

\section{Abstrak}

Sebelum wahyu Al-Qur'an diturunkan kepada Nabi Muhammad SAW, konsep wahyu telah ada didalam budaya masyarakat arab pada masa itu. Konsep pada saat itu terkait pada puisi dan ramalan yang dianggap datang dari dunia jin yang disampaikan kepada penyair dan peramal melalui proses pewahyuan. Wahyu merupakan mukjizat yang luar biasa diturunkan kepada nabi dan Rasul. Wahyu ini diturunkan sesuai dengan sesuatu yang akan terjadi pada zaman ini, wahyu diturunkan melalui malaikat Jibril, lalu malaikat Jibril menyampikannya kepada nabi dan rasul yang dikehendaki oleh Allah. Wahyu tidak hanya turun kepada Nabi Muhammad saja, akan tetapi juga turun kepada nabi-nabi sebelum Nabi Muhammad. Disamping itu, dalam konteksnya, wahyu yang turun kepada Nabi Muhammad saja tidak haya al-qur'an, akan tetapi juga berupa hadis, baik berupa hadis qudsi maupun hadis Nabawi. Diantara kemurahan Allah Swt terhadap manusia bahwa dia tidak saja memberikan sifat yang bersih yang dapat membimbing dan memberi petunjuk kepada mereka kearah kebaikan, tetapi juga dari waktu ke waktu dia mengutus seorang rasul kepada umat manusia.

Kata kunci: konsep, wahyu, al-qur'an 


\section{Pendahuluan}

Kajian kritis terhadap wahyu dalam ulumul Qur'an dengan berbagai metode dan pendekatannya selalu mengalami perkembangan yang dinamis seiiring dengan tuntutan dan perkembangan pemikiran manusia, dihubungkan dengan perkembangan zamannya. Hal ini dikarenakan, wahyu sebagai bagian dari seputar kajian Al-Qur'an (ma Hawla Al-Qur'an) senantiasa menerima perubahan dalam pemahaman, meski terkadang menimbulkan kontroversi ditengah masyarakay Islam. ${ }^{1}$

Wahyu secara bahasa diartikan sebagai isyarat yang cepat, bisa juga diartikan sesuatu yang diturukan, disingkapkan atau diumumkan. Wahyu merupakan sebuah pencerahan, sebuah bukti atas realitas dan sebuah penegasan kebenaran. Ia adalah sebuah tanda yang jelas, sebiah bukti atau indikasi, makna atau signifikansi, bagi seorang pemerhati, yang harus diamati, direnungkan dan dipahami. Dari wahyu akan memunculkan gagasan, saran, pemikiran, penemuan ilmiah, tatanan sosial yang egaliter, dan ditemukannya kebenaran ilahi, memperkaya pengetahuan, petunjuk, dan kesejahteraan manusia serta membebaskan fikiran-fikiran, koral, dan emosi- emosi yang terbelenggu dan meninggikan harkat dan martabat manusia-manusia yang tertindas oleh kekuatan-kekuatan kezaliman, tirani dan tahayyul. ${ }^{2}$

Segala yang ada di jagat raya, bumi, langit, matahari dan bulan, siang dan malam, terang dan gelap, pergantian musim, semuanya merupakan wahyu jika dipandamg dari sisi diatas, dan tanda-tanda bagi orang-orang yang hidup dan memiliki kebijaksanaan dan wawasan. Begitu pula gejala-gejala alam, social dan historis dalam semua manifestasinya, misteri dan keajaiban, semuanya adalah dipandang juga sebagai wahyu, serta ia diartikan sebagai tanda-tanda dan bukti kebenaran bagi siapapun yang dapat mengeksplorasinya, menyelidiki dan menemukan kebenaran serta memahaminya. Demikian juga, wahyu juga dipahami sebagai sesuatu yang dibisikan ke dalam sukma, yang diilhamkan, dan merupakan isyarat yang cepat yang lebih mirip pada sesutau yang dirahasiakan dari pada dilahirkan; Sesuatu yang dituangkan dengan cara cepat dari Allah SWT kedalam dada para nabi-Nya. Wahyu merupakan kebenaran yang langsung disampikan Allah SWT kepada para nabi-Nya untuk disampaikan kepada para umatnya.

\footnotetext{
${ }^{1}$ Badrudin, Ulumul Qur'an, (Serang: A-Empat, 2020), hlm 24.

${ }^{2}$ Ziaul Haque, Wahyu dan Revolusi, terj. E. Setiyawati Al-Khattab (Yogyakarta: LKiS, 2000), hlm.9.
} 
Perkembangan dan kemajuan berpikir manusia senantiasa disertai oleh wahyu yang sesuai dan dapat memecahkan problem-problem yang dapat dihadapi oleh kaum setiap rasul saat itu, sampai perkembangan itu mengalami kematangannya. Allah menghendaki agar risalah Muhammad muncul didunia ini. Maka diutuslah beliau disaat manusia sedang manusia mengalami kekosongan para rasul, untuk menyempurnakan"bangunan" saudara-saudara pendahulunya dengan syariat yang universal dan abadi sera dengan kitab yang diturunkan kepadanya, yaitu Al-Qur'anul Karim. ${ }^{3}$

\section{Definisi Wahyu Al-Qur'an}

Al-Wahyu (wahyu) adalah kata masdar (infinitif). Dia menunjuk pada dua pengertian dasar, yaitu, tersembunyi dan cepat. Oleh sebab itu, dikatakan, "Wahyu ialah informasi secara tersembunyi dan cepat yang khusus ditujukan kepada orang tertentu tanpa diketahui orang lain. Namun, terkadang juga bermaksud al-muha, yaitu pengertian isim maf'ul, maknanya yang diwahyukan, dalam Al-Qur'an wahyu diulang sebanyak 78 kali, yaitu dalam bentuk kata benda (isim) sebanyak 6 kal, dan dalam bentuk kaya kerja (fi'il) sebanyak 72 kali. $^{4}$

Secara etimologi (lugawi) pengertian wahyu dapat dilihat: ${ }^{5}$

a. Ilham al-fitri li al-insan (ilham yang menjadi fitrah manusia), seperti wahyu terhadap ibu Nabi musa

b. Ilham yang berupa naluri pada binatang, seperti wahyu kepada lebah

c. Isyarat yang cepat melalui isyarat, seperti isyarat Zakariya yang diceritakan Al-Qur'an.

d. Bisikan setan untuk menghias yang buruk agar tampak indah dalam diri manusia.

e. Apa yang disampaikan Allah kepada para malaikat-Nya berupa suatu perintah untuk dikerjakan.

Secara terminologis pengertian wahyu sebagai berikut: ${ }^{6}$

a. Muhammad 'Abd al-'Adzim az-Zarqani mendefinisikan wahyu sebagai pemberitahuan Allah SWT kepada hamba-Nya yang terpilih mengenai segala sesuatu yang ia kehendaki untuk

\footnotetext{
${ }^{3}$ Manna Khalil al-Qattan, Studi Ilmu-Ilmu Al-Qur'an, (Bogor: Litera AntarNusa, 2016), cet ke-17, hlm.10-12.

${ }^{4}$ Muhammad Fuad 'Abd al-Baqi, Al-Mu'jam al-Mufahras li Alfaz al-Qur'an al-Karim (Beirut: Dar al-Fikr, 1981), hlm. 468-469

${ }^{5}$ Manna' al-Qattan, penganta...,hlm. 34

${ }^{6}$ Badrudin, Ulumul Qur'an, (Serang: A-Empat, 2020), hlm 30-31.
} 
dikemukakan-Nya, baik berupa petunjuk maupun ilmu, namun penyampaiannya dengan cara rahasia dan tersembunyi serta tidak serta terjadi dalam manusia biasa.

b. Muhammad Abduh dalam Risalah at-Tauhid mengatakan, wahyu adalah pengetahuan yang didapati seseorang dalam dirinya dengan suatu keyakinan bahwa pengetahuan itu datang dari Allah, baik dengan melalui perantaraan ataupun tidak. Yang pertama melalui suara yang terjelma dalam telinganya atau bahkan tanpa suara.

c. Hasbi alsh-Shiddieqy memberi pengertian wahyu sebagai menerima pembicaraan secara rohani, kemudian pembicaraan itu berbentuk dan tertulis dalam hati.. Wahyu merupakan limpahan ilmu yang dituangkan Allah kedalam hati para Nabi dan Rasul. Dengan demikian terukirlah ibarar-ibarat atau gambaran-gambaran, lalu dengan ibarat-ibarat itu nabi mendengar pembicaraan yang tersususn rapi.

Al-Qur'an sebagai kitab suci telah dipelajari luas oleh pemikir muslim maupun yang lain secara kristis maupun tidak. Bagi kaum muslim mapun lain, secara kritis mapun tidak. Bagi kaum muslim, Al-Qur'an sebagai kompilasi "Firman Tihan” tidak merujuk pada sebuah kitab yang diilhami atau dipengaruhi oleh-Nya atau ditulis dibawah bimbingan ruh-Nya.

Hubungan komunikatif antar tuhan dan manusia pada dasarnya bersifat timbal balik:

-Tuhan kepada Manusia

-Manusia kepada Tuhan

Didalam Al-Qur'an wahyu memperoleh tempat yang sangat khusu, diperlakukan secara istimewa, sesuatu yang misterius, rahasia yang tidak dapat diungkap oleh pikiran manusia biasa.Untuk itulah diperlukan perantara yang disebut "nabi", dalam islam wahyu artinya "perkataan Tuhan yang hakikatnya merupakan konsep linguistik.

Secara teologis diyakini bahwa al-Qur'an baik lafal maupun makna dalam firman Allah yang didiktekan Jibril kepada nabi Muhammad. Al-Qur'an sebagai cermin atau kamera foto yang sanggup memantulkan seribu satu wajah sesuai dengan orang yang datang untuk bercermin dan berdialog dengan nya. Ketika membaca Al-Qur'an kita di hadapkan pada berlapis-lapis penafsiran. Jika di urut, penafsiran pertama Al-Qur'an adalah yang disebut Jibril. Penafsiran yang kedua tentu saja Nabi Muhammad. Keterlibatan Nabi Muhammad dalam penafsiran Al- 
Qur'an berlangsung dalam data level. Pertama, proses pengungkapan dalam bahasa Arab kedua penafsiran atas Al-Quran yang kemudian disebut Hadits. ${ }^{7}$

\section{Konsep Wahyu Menurut Al-Qur'an}

Wahyu adalah tanzil/munazzal, diturunkan langsung. Dalam artian,apa yang diterima Nabi adalah murni sebagi firman Allah SWT secara utuh . Tidak terkandung didalambya penafsiran dan pengalihan bahasa oleh malaikat atau oleh nabi sendiri. Dari Allah SWT sudah berbahasa Arab, bukan dialih bahasakan kedalam bahasa Arab oleh Nabi SAW. oleh karenanya teks Al-Qur'an, walalupun bagaimanapun tidak akan sama dengan teks buatan penyair, ataupun jampi-jampi paranormal.

Pasa dasarnya, hubungan komunikatif antar Tuhan dan manusia bersifat Timbal balik : 1) dari Tuhan kepada manusia dan 2) dari manusia kepada kepada Tuhan. Didalam Al-Qur'anw Wahyu memperoleh tempat yang sangat khusus, diperlakukan secara istimewa, sesuatu yang misterius, rahasia yang tidak dapat diungkap oleh pikiran manusia biasa. Untuk itulah diperlukan perantara yang disebut "Nabi”. Dalam Islam, Wahyu artinya “ perkataan” Tuhan yang pada hakikatnya merupakan konsep linguistik. ${ }^{8}$

Obyek utama wahyu didalam Al-Qur'an adalah Nabi Muhammad. "Demikian, kami telah mengutus kamu pada suatu umat yang sungguh telah berlalu beberapa unat sebelumnya,dupaya kamu membacakan kepada mereka (Al-Qur'an) yang kamu wahyukan kepadamu, padahal mereka kafir kepada Tuhan yang MahaPemurah. Katakanlah:’Dia-lah Tuhanku tidak ada tuhan selain Dia; hanya kepada-Nya aku bertawakkal dan hanya kepadaNya aku bertaubat. ${ }^{9}$

Masyarakat kontemporer Nabi keheranan karena ia menerima wahyu untuk memberi peringatan dan kabar gembira. Wahyu yang diterima Nabi Muhammad memiliki asal-usul ilahiah, seperti telah diterima Nabi Muhammad memiliki asal-usul ilahiah, seperti yang telah ditegaskan oleh Al-Qur'-!: 'Dan tiadalah yang diucapkannya itu (Al-Qur'an) menurut kemapuan hawa nafsunya. Ucapannya itu tiadalain hanyalah wahyu yang diwahyukan (kepadanya)". Namun, yang menjadi kunci adlaah bagaimana proses pewahyuan Al-Qur'an kepada Nabi Muhammad SAW.

\footnotetext{
${ }^{7}$ Komarudin Hidayat, Memahami Bahasa Agama: Sebuah kajian Hermeneutik (Jakarta : Paramadina, 1996),hlm.6.

${ }^{8}$ Toshihiko Izutsu, Relasi Tuhan..., 2003, hlm. 165-166.

${ }^{9}$ QS. ar-Ra'd: 30
} 
Salah satu gambaran Al-Qur'an yang paling jelas tentang mekanisme wahyu terdapat dalam QS. Al-baqarah : 97 yang mengungkapkan bahwa "Jibril telah menurunkan (yakni pesan-pesan ketuhanan) kedalam hati Nabi dengan seizin Tuhan. ${ }^{10}$

Allah menurunkan wahyu kepada para rasul-Nya dengan dua cara:

Melalui Jibril, malikat pembawa wahyu, ada dua cara penyampaian wahyu oleh malaikat kepada rasul; pertama, datang dengan suara seperti suara lonceng, yaitu suara yang amat kuat yang dapat mempengaruhi kesadaran, sehingga ia dengan segala kekuatannya siap menerima pengaruh itu.

Tanpa melalui perantaraan, diantaranya ialah mimpi yang benar bagi para nabi adalah wahyu yang wajib diikuti, ialah mimpi Nabi Ibrahim agar menyembelih anaknya Ismail. Allah SWT berifirman;

"Maka kami beri dia kabar gembira dengan anak yang sangat sabar. Maka tatkala anak itu telah sampai (pada umur sanggup) berusaha bersama-sama Ibrahim, lalu Ibrahim berkata: "Wahai anakku, sesungguhnya aku melihat dalam mimpi bahwa aku menyembelihmu. Maka fikirkan pendapatmu!" Ia menjawab "Wahai bapakku, kerjakanlah apa yang diperintahkan kepadamu; insya Allah engkau akan mendapatiku termasuk orang-orang yang sabar". Tatkala keduanya telah berserag diri dan Ibrahim mebaringkan anaknya aras pelipisnya, nyatalah kesabaran keduanya.

\section{Cara Wahyu Allah Turun kepada Para Rasul}

Allah memberikan Wahyu kepada Para Nabi dan Rasul ada yang melalui perantara dan ada yang tidak melalui perantara.

Yang pertama: melalui Jibril, malaikat pembawa Wahyu.

Yang kedua: tanpa melalui perantara, diantara nya ialah mimpi yang benar dalam tidur.

- Mimpi yang benar didalam tidur.

Dari Aisyah RA, dia berkata: sesungguhnya apa yang apa-apa yang mula-mula terjadi bagi Rasulullah SAW adalah mimpi yang benar diwaktu tidur. Beliau tidaklah mimpi kecuali mimpi itu datang bagaikan datangnya pagi hari.

${ }^{10}$ QS. Al-Baqarah: 97 
Hal itu merupakan persiapan bagi Rasulullah untuk menerima Wahyu dalam keadaan sadar, tidak tidur. Didalam Al-Qur'an Wahyu diturunkan ketika beliau dalam keadaan sadar, kecuali bagi orang yang mendakwahkan bahwa surat Al-Kautsar diturunkan melalui mimpi, karena adanya satu hadis mengenai hal itu. Didalam shahih muslim, dari Anas RA ia berkata:

“Ketika Rasulullah SAW pada suatau hari berada di antara kami didalam mesjid, tiba-tiba ia mendekur, lalu mengangkat kepala beliau dalam keadaan tersenyum. Aku tanyakan kepadanya, 'apakah yang menyebabkan engkaulah tertawa wahai Rasulullah?' ia menjawab: 'tadi telah turun kepada ku sebuah surah.' Lalu beliau mengucapkan, “Bismillahir-rahmanir-rahim, Inna 'athoina kal kautsar; fasholli lirobbika wanhar; Inna syaniaka jual abthar'.

Mimpi yang benar itu tidaklah khusus bagi para rasul saja. Mimpi yang demikian itu tetap ada pada kaum mukminin, sekalipun mimpi mimpi itu bukan Wahyu; hal itu seperti dikatakan Rasulullah SAW. "Wahyu telah terputus, tetapi berita-berita gembira itu ada, yaitu mimpi orang mukminin".

Mimpi yga benar bagi para nabi diwaktu tidur itu merupakan bagian pertama dari sekian macam cara Allah berbicara seperti disebutkan didalam firman Allah.

"Dan tidaklah patut bagi seorang manusia bahwa Allah akan berbicara kepadanya kecuali dengan perantara Wahyu atau dari belakang tabir atau dengan mengutus utusan (malaikat) lalu diwahyukan kepadanya dengan izinnya apa yang dia kehendak sungguh Allah Maha Tinggi lagi Maha Bijaksana.”(Q.S As-Syura :51).

- Yang lain ialah Kalam ilahi dari balik tabir tanpa melalui perantara yang demikian terjadi pada Nabi Musa AS.

"Dan ketika Nabi Musa datang untuk (munajat) pada waktu yang telah kami tentukan dan Tuhan telah berfirman (langsung) kepada-nya (Musa) berkata, "Ya Tuhanku, tampakkanlah (dirimu) kepadaku agar aku dapat melihat engkau". (Al-A'raf : 143).

Demikian Pula menurut pendapat yang paling sah, Allah pun telah berbicara secara langsung kepada Raaul kita Muhammad SAW pada malam isra dan Mi'raj. Yang demikian ini yang termasuk bagian kedua dari apa yang disebutkan oleh ayat di atas (atau dari balik tabir). Dan dalam Qur'an Wahyu macam ini pun tidak ada.

Jadi pada intinya Wahyu Allah turun kepada Para nabi-Nya itu adakalanya tanpa perantara, seperti yang telah kami sebutkan di atas, misalnya mimpi yang benar di waktu tidur dan malam 
ilahi dari balik tabir dalam keadaan jaga yang disadari; dan adakalanya melalui perantara malaikat Jibril.

Wahyu dengan perantara malaikat Jibril inilah yang sering terjadi pada Nabi Muhammad SAW, karena Qur'an diturunkan dengan Wahyu macam ini.

Ada dua cara penyampaian Wahyu oleh Malaikat kepada Rasul: ${ }^{11}$

Cara pertama : datang kepadanya suara seperti dencingan lonceng dan suara yang amat kuat yang mempengaruhi faktor-faktor kesadaran, sehingga ia dengan segala kekuatannya siap menerima pengaruh itu. Cara ini yang paling berat buat Rasul. Apabila Wahyu yang turun kepada Rasulullah SAW dengan cara ini, maka ia mengumpulkan segala kekuatan kesadarannya untuk menerima, menghafal dan memahaminya. Dan suara itu mungkin sekali suara kepakan sayap-sayap para makaikat.

Cara kedua: Malaikat menjelma kepada Rasul sebagai seorang laki-laki dalam bentuk manusia. Cara yang demikian itu lebih ringan dari cara yang sebelumnya, karena adanya kesesuaian antara pembicara dengan pendengar. Rasul merasa senang sekali mendengarkan dari utusan pembawa Wahyu itu, Karena merasa seperti seorang manusia yang berhadapan dengan saudaranya sendiri.

\section{Mukjizat Al-Qur'an}

Para Rasul itu, perlu mempunyai tanda untuk menguatkan bahwa segala apa yang disampaikan itu benar-benar dari Tuhan semesta Alam. Tanda-tanda itu harus dapat mengalahkan atau melebihi segala kejadian yang besar. Untuk itu manusia semuanya tidak akan dapat memperbuat atau meniru perbuatan luar biasa yang dilakukan Nabi. Tanda-tanda itu namanya mukjizat, yang menurut kata aslinya, berarti yang dapat mengalahkan.

Oleh karena itu, tentu saja Mukjizat Nabi terjadi dari beberapa hal yang mengherankan dan mengalahkan kecakapan manusia dan memang maksud dan gunanya untuk mengatasi atau mengalahkan apa yang didapat oleh manusia yang tidak mempunyai mukjizat. ${ }^{12}$

Manusia yang telah mengetahui Mukjizat itu, terbagi menjadi dua golongan; satu golongan yang masih bersih hatinya apabila mereka kedatangan kebenaran ia akan tunduk dan mengikuti akan segala petunjuknya. Baik dalam pekerjaan sehari-hari ataupun urusan kepercayaan

\footnotetext{
${ }^{11}$ Badrudin, Ulumul Qur'an, (Serang: A-Empat, 2020), hlm 39.

${ }^{12}$ Imam Zarkasyi, Ushuluddin Ilmu 'Aqaid...., hlm.60-61
} 
didalam hatinya mereka itulah orang-orang yang insaf, lagi berbudi mulia. Mereka itulah orang yang berbahagia.

Segolongan lagi, ialah orang-orang yang terpengaruh oleh hawa nafsunya, maka mereka dengan sengaja tidak hendak melihat cahaya kebenaran, dan mencari-cari jalan lain. Hal itu disebabkan oleh kesombongan mereka, atau karena merasa hina kiranya mengikuti kebenaran itu, atau karena Hasad atau iri kepada yang membawa kebenaran, atau telah terlanjur dalam kemurkaan segar kembali ke jalan kebenaran yang semestinya. Mereka itulah orang-orang yang sesat; dan mereka itu adalah orang-orang yang teraniaya oleh perbuatannya sendiri.

Apabila orang-orang banyak tadi membohongkan para Rasul atau mengajak serta mendurhakainya, maka Allah memberikan mukjizat yang dapat menolak tuduhan mereka dan menutup mulut mereka yang hanya menuduh tidak ada bukti. Maka dari itu, pada tiap-tiap kedatangan Mukjizat, tentu bersama dengan tantangan yalng maksudnya meminta kepada orang-orang yang membohongkan supaya membuat atau mengadakan seperti mukjizat tadi. Dan supaya mereka mengetahui dan mengerti bahwa mereka tidak dapat dan tidak akan dapat melakukan hal serupa dengan mukjizat tersebut.

Demikian Allah memberi tanda persaksian bagi kebenaran Para Rasul. Mukjizat itu tetap menjadi bukti kebenaran, meskipun masih banyak orang yang mengingkari nya, adanya orangorang yang yang ingkar akan kebenaran setelah adanya bukti itu tidak akan mengurangi kebenaran para Rasul.

\section{Kesimpulan}

Sebelum wahyu Al-Qur'an diturunkan kepada Nabi Muhammad SAW, konsep wahyu telah ada didalam budaya masyarakat arab pada masa itu. Wahyu merupakan sebuah pencerahan, sebuah bukti atas realitas dan sebuah penegasan kebenaran. Ia adalah sebuah tanda yang jelas, sebiah bukti atau indikasi, makna atau signifikansi, bagi seorang pemerhati, yang harus diamati, direnungkan dan dipahami. Allah menurunkan wahyu kepada para rasul-Nya dengan dua cara: Melalui Jibril, malikat pembawa wahyu, ada dua cara penyampaian wahyu oleh malaikat kepada rasul; pertama, datang dengan suara seperti suara lonceng, yaitu suara yang amat kuat yang dapat mempengaruhi kesadaran, sehingga ia dengan segala kekuatannya siap menerima pengaruh itu. Tanpa melalui perantaraan, diantaranya ialah mimpi yang benar bagi para nabi adalah wahyu yang wajib diikuti, ialah mimpi Nabi Ibrahim agar menyembelih anaknya Ismail 


\section{Daftar Pustaka}

Al-Qattan, Manna' Khalil. (tth). Mabahits fi 'Ulum al-Qur'an. al-Qahirah : Maktabah Wahbah.

Al-Zarqani, Muhammad Abd al-Azim. (tth). Manahil Al 'Irfan fi 'Ulumi Al-Qur'an. Jilid 1., Beirut: Daru Al Fikri.

Az-zarkasyi, Al-Imam Badruddin Muhammad bin 'Abdullah. (1972). Al-Burhan fi 'Ulumil Qur'an. Jilid 1.ttp.: Isa al- Babiy al-Halabiy.

Badrudin. (2020). Ulumul Qur'an. Serang: A-Empat

Ziaul Haque. (2000). Wahyu dan Revolusi, terj. E. Setiyawati Al-Khattab. Yogyakarta: LKiS. 